\title{
ANALYSIS OF THE CREATION OF A MODERN PHARMACEUTICAL SUPPORT SYSTEM IN UKRAINE IN A RETROSPECTIVE DEVELOPMENT OF THE STATE AND CIVIL SOCIETY RELATIONS
}

\author{
Liliia Hala \\ Department of Organization and Economy of Pharmacy \\ Bogomolets National Medical University \\ 13 Shevchenko blvd., Kyiv, Ukraine, 01601 \\ hala.liliia@gmail.com \\ Hanna Panfilova \\ Department of Organization and Economy of Pharmacy \\ National University of Pharmacy \\ 53 Pushkinska str., Kharkiv, Ukraine, 61002
}

\begin{abstract}
The effectiveness of the system of pharmaceutical supply to the population depends on the proper interaction of the state and market mechanisms for regulating the interests of all subjects of the pharmaceutical market for the implementation of the social policy of the state regarding the availability of quality and effective medicines for the population. In the context of healthcare reform, the issues of assessing the main stages of the development of the pharmaceutical supply system of the population become especially relevant.

Aim. Determination of key, from organizational, economic and social points of view, stages of formation of the domestic system of pharmaceutical supply of the population, analysis of the main tendencies of its development in retrospect years.

Materials and methods. The materials of the research were selected by the regulatory acts, the data of the specialized literature, certain aspects of activity of subjects of the pharmaceutical market, etc. Methods such as historical, informational-analytical, analytical-comparative, systemic, logical, hypothetical-deductive and generalization were used.

Results. Based on the conducted research, five stages of the formation of the pharmaceutical supply system have been identified and outlined, which differ fundamentally across the range of criteria for analyzing effectiveness in building relationships between the state, civil society and the professional community. These stages were elaborated in accordance with the results of the analysis of the nature of relations between the authorities and society under the conditions of gradual transition from paternalistic to the elements of the patient-oriented model of medical and pharmaceutical services to the population:

1) 1990-1993;

2) 1994-2000;

3) 2001-2007;

4) 2008-2013;

5) from 2014 to the present.

It has been proved that the stages of development of the domestic pharmaceutical supply system depend to a large extent on the nature of the influence of external environmental factors: changes of political elites in the country, global and internal financial crises, changes of priorities of the state development, breaking of social consciousness of the population against the background of political crisis, etc. It should be noted that the most important in terms of positive, first of all socio-economic, development characteristics is the fourth stage of formation (2008-2013) of the domestic system of pharmaceutical supply of the population. The last period (since 2014) is characterized by the existence of a crisis of relations between all subjects in the system of pharmaceutical provision of the population against the background of systemic transformations in the state, strengthening of the role of public professional associations and critical raising of public expectations from the state regarding the organization of providing affordable medical care to the population. and pharmaceutical assistance in the face of mass impoverishment.

Conclusion. The basic stages of the formation of the domestic pharmaceutical supply system are defined and their characteristics are envisaged, which allow to form in the future fundamentally new approaches to building rational, economically speaking, and simultaneously socially responsible relations between different subjects in the pharmaceutical market.

Keywords: pharmaceutical supply system, health care, state regulation of pharmaceutical activity, pharmacy establishments, civil society.
\end{abstract}

DOI: $10.21303 / 2504-5679.2019 .001003$ 


\section{Introduction}

The peculiarity of the functioning of the pharmaceutical supply system in any country is due to several factors, among which the following deserve attention. First, the regulated circulation of medicines (drugs) in the pharmaceutical market (FM) emerges as an important socially important mechanism, the effective functioning of which enables the exercise of the constitutional right of citizens to preserve the fundamental value in society, namely health and human life. Second, FM is a consumer market sector in which market relations between different entities operate. Considering the aforementioned, the effective functioning of the system of pharmaceutical supply to the population depends on the proper interaction of the state and market mechanisms of regulating the interests of all subjects of the FM for the implementation of the social policy of the state regarding the availability of quality and effective drugs for the population. Thus, the effective functioning of the FM must ensure that the social and economic interests of all its subjects are balanced. The nature of the interaction between the categories of public health and the indicators of the level of solvency of citizens depends on the general structure of expenditures on pharmaceutical supply of the population, which, in the final analysis, supply and demand in the market of medicines, the corresponding structure of FM, sales volumes, assortment of goods, etc.

Despite the market nature of the functioning of various economic entities, the FM is increasingly focusing on increasing the social responsibility of the pharmaceutical business to society, above all, providing the population with quality, effective and affordable drugs. A special place in building this type of relationship in the pharmaceutical supply system belongs to public professional organizations and unions. The most effective functioning of the pharmaceutical community and professional self-government, which is based on public organizations, associations, unions, in cooperation with state structures, should ensure the formation of socially responsible relations in the modern FM in Ukraine. Currently, the country's health care system is at a turning point. The first stages of public relations pharmaceutical reform, which began in 2017, demonstrated the depth of those socio-economic problems that have plagued the population for many years. Given the high level of public expectations for improving the availability of medical and pharmaceutical care, the question of changing the formats of relationships between entities in the FR and in the health care system is emerging as socially significant. Against this background, the analysis of the stages of formation of the domestic pharmaceutical supply system in order to identify the directions of its effective development is relevant and of social importance.

Problems of formation of the system of pharmaceutical supply of the population in terms of relations between the state and civil society have been repeatedly researched by scientists. Thus, the priorities for reforming the system of state and social regulation in pharmacy were studied by Nemchenko A. S., Susharina I. V., Khomenko V. M. [1]; questions of introduction of concept of social responsibility in practical pharmacy, approaches to development of social responsibility during professional training - Gromovik B. P., Tkachenko N. O. [2]; the main stages of the formation of social pharmacy in the world and in Ukraine since the 50's of the twentieth century - Kotvitska A. A., Kubareva I. V. [3]; expediency of participation of public pharmaceutical organizations in standardization of processes of pharmaceutical supply of population - Unguryan L. M. [4]; questions of social responsibility of pharmaceutical business and directions of its regulation in accordance with international standards - Bratishko Yu. S. [5]. Also, the work of foreign authors has explored the issue of strengthening the role of pharmaceutical workers and public health services, which requires changes in the behavior of both professionals and society Eades C. E., Ferguson J. S., O’Carroll R. E. [6]; pharmacists' experience in healthcare teams, providing patient care systems - Bush P. W., Daniels R. [7]; pharmacists' involvement in optimal drug use, pharmacotherapy management, which reduces overall health care costs - Blouin R. A., Adams M. L. [8].

Aim - identification of key, from organizational, economic and social points of view, stages of formation of the domestic system of pharmaceutical supply of the population, analysis of the main tendencies of its development in retrospect years. 


\section{Materials and methods}

The subject of the research was the historical processes of development of the national health care system and pharmaceutical supply of the population in the context of state formation and formation of civil society, and the objects - mechanisms of state regulation of FM of Ukraine and market development of relations between different entities in the process of providing the population with medical and pharmaceutical assistance, basic approaches in the organization of pharmaceutical activity at different stages of formation of the national health care system. The materials of the study selected regulatory legal acts (RLAs) regulating the organization of provision of medical and pharmaceutical services to the population, data of special literature, which outlines the main directions of development of the pharmaceutical supply system of the population, certain aspects of the activity of subjects of FM and indicators of its development in the dynamics years (volume of retail sales and hospital supplies of drugs in monetary and physical terms, level of provision by pharmacy establishments). In theoretical studies, we have used such methods as historical (study of stages of development in chronological sequence), information-analytical (detection of common and different between different stages of development), analytical-comparative (search for properties of certain objects in comparison with others), systemic (establishing links between the elements of the system under study), logical (establishing logical patterns of development), hypothetical-deductive (hypothesis and deduction by deduction) and generalization (results of the study are summarized).

The system of pharmaceutical supply to the population in the classical definition appears as an integral structure, characterized not only by the complexity of the construction, but also by close links with the environment $[1,9]$. Therefore, a retrospective analysis of the development of the said macrostructure of the country was considered by us, above all, in the context of the formation of the Ukrainian state (declaration of independence of Ukraine in 1990), the development of civil society and changes in the worldviews of people regarding the attitude to "health" as the highest value in the humanistic oriented states.

\section{Results of the research}

Summarizing the results of the theoretical studies, we have identified the following stages of development of the system of pharmaceutical supply of the population, outlined the main trends and problems. So, in the early 1990s, when Ukraine gained independence, the issue of providing drugs to the population was acute. From the planned economy under the Law "On Enterprises in Ukraine" of 26.03.1991, the country embarked on the path of its liberalization and introduction of market relations in almost all sectors of the economy. In 1992, the decline in our own production of drugs was maximum, during this period, Ukraine received $\$ 280$ million worth of drugs at wholesale prices, but it was three times less than during the Soviet Union (USSR) period. However, as of January 1, 1992, there were 6,413 pharmacies operating in the system of the Ministry of Health of Ukraine, most of them located in cities and towns. The population served by one pharmacy in average was 7.9 thousand people, which was significantly higher than in Europe [10].

The need for market transformation for all parts of the macroeconomic complex of the state, including FM, became relevant, given the regulatory influence of market relations on establishing the necessary proportions between the volume of needs of society in certain goods and their production. Under the conditions of transition to a market economy in accordance with the Laws of Ukraine "On privatization of state property", "On privatization of small state-owned enterprises (small privatization)", adopted in 1992, processes of privatization of pharmaceutical enterprises, demonopolization, creation of alternative structures were observed, including non-state ownership, even in socially-oriented industries. The spontaneous, irrational opening of pharmacies has begun with the simultaneous catastrophic reduction of their number in rural areas due to the unprofitable situation for owners, the creation of associations and pharmacy chains: "Arnica", "Falby", "Med-Service", "Zi" and others. (1993-1995). There are also the first powerful distribution companies - "Alba" (1993), “BaDM" (1994), “Optima Farm" (1994), "BBC-LTD” (1994), "Venta LTD” (1995).

According to the theory of market relations, social protection of the person in the initial stages of the formation of relations between capital and labor resources is not a dominant in society. 
Thus, it was during this period that the centralized system of providing the population with drugs, which had existed in the former USSR for several decades, was completely destroyed in Ukraine. The state has withdrawn from the fulfilment of the financial obligations declared in the Constitution of Ukraine regarding the protection of public health. It is at this time that the shadow market, the production and circulation of counterfeit drugs, develops, and aggressively advertises biologically active additives of unknown production. Domestic pharmaceutical manufacturers are on the verge of bankruptcy. This stage of market relations is characterized by low level of development of pharmaceutical industry enterprises, low physical and socio-economic availability of drugs for the population, as well as inefficiency of functioning of state mechanisms of regulation of quality of medicines at all stages of their promotion through the distribution network, from import into the country to sale to the end consumer pharmacies. Analyzing the data of the specialized literature, it can be argued that the government at that time did not realize that one of the guarantors of Ukraine's sovereignty was the effective pharmaceutical supply of the population $[10,11]$. However, despite the systemic crisis in the state, in 1992 the "Comprehensive Program for the Development of the Medical, Veterinary and Microbiological Industry, Improving the Supply of the Population and Livestock with Medicines, Medical and Veterinary Equipment for 1992-1996" was developed and adopted for construction of new and reconstruction of existing enterprises, expansion of the range of production of drugs and medical devices. Positive during this period (1992) was also the establishment of important institutions, which were subordinate to the Ministry of Health (MOH) of Ukraine and had control functions in the sphere of drug trafficking, in particular, the State Inspectorate for Quality Control of Drugs, the Pharmacological Committee, Pharmacopoeial Committee, the successors of which still play an important role in the regulation of pharmaceutical activity in Ukraine. In 1993, significant changes occurred in the structure of pharmacy management. Thus, the State Committee of Ukraine for Medical and Microbiological Industry (SCUMMI) and the Ukrainian Association "Ukrpharmacy" were created. Already from this period, it can be argued about the gradual revival of the national health care system and pharmaceutical supply of the population as an important component of the country's macroeconomic complex, the effective functioning of which creates favourable conditions for social stability and well-being of the population. Thus, the first stage of development lasted from 1990 to 1993.

The second stage of development begins in 1994, when the Ukrainian authorities signed the Partnership and Cooperation Agreement between Ukraine and the European Community and their Member States and declared their desire for European values and standards, but the processes of divestiture of pharmacies did not contribute to the stated purpose. According to experts, at that time, there were no private drugstore chains in any European Union (EU) country that actually forced the society into its own understanding of the drug supply process in accordance with its commercial interests. It was at the second stage of the development of the domestic pharmaceutical supply system that an unmistakably significant event took place, namely in 1996 the Law of Ukraine "On Medicines" was voted, according to which it was envisaged to regulate by-laws all issues related to drug trafficking in Ukraine. During this period, qualitative structural changes took place on the domestic FM. Thus, in the use of drugs, the share of domestic drugs began to increase gradually, but for the vast majority of the population, medicines remained almost inaccessible. Therefore, at the state level, the question arises of the development and implementation of effective mechanisms to ensure the physical and socio-economic availability of medicines for the general population. At that time, part of the physical shortage of drugs was satisfied with the efforts of domestic manufacturers, although the level of socio-economic availability of drugs remained very low. Thus, gradually FM drugs began to be saturated, in the vast majority due to drugs from domestic production and generics of Indian and Eastern European production. By the end of 1997, drugs were manufactured in Ukraine $60 \%$ more than in 1992. In 1998, drugs were imported into Ukraine from almost 50 countries [10]. The logical consequence of the development of the domestic system of pharmaceutical supply to the population and the gradual transition to the implementation of European norms and requirements in the pharmaceutical sector of the economy was the large-scale development and implementation of a series of steps, regulating drug trafficking in Ukraine. 
At this stage, the idea of reforming the pharmaceutical health care industry was to create a system of providing the population with affordable and quality drugs, as recommended by the World Health Organization (WHO) "Focus on the Patient" (1998) [4]. This was an important qualitative breakthrough in the state's vision for the development of the national health care system.

In the context of the economic crisis of September 1998, the fall of the national currency, the growth of competition in the pharmaceutical sector, the decrease in the level of solvency of the population, in Ukraine there was a tendency to increase the level of wholesale and retail prices for drugs. However, due to the lack of a consistent national drug policy under the slogan of reforming the pharmaceutical sector within the Ministry of Health of Ukraine, organizational structures were created, with provisions for activities declaring comprehensive functions that could not be put into practice in Ukrainian realities (1999-2000 - National agency on quality and safety control of food, medicines and medical products). This structure was to combine: production control (until now State Committee on Biomedicine Industry), control in the field of drug development, registration and use (Pharmacological Committee and Committee on Immunobiological Preparations), control in the field of implementation (State Inspectorate for Quality Control of drugs). That was an attempt to build a centralized model for regulating drug trafficking in Ukraine. However, this state structure did not exist for 2 years. By decree of the President of Ukraine dated July 24, 2000, No. 918/2000, the activity of the said body was cancelled. Following the elimination of the above-mentioned National Agency in 2000, a State Department for Quality Control, Safety and Production of Drugs and Medical Devices was formed within the Ministry of Health, despite its functioning in the country of the State Inspectorate for Quality Control of Drugs. Thus, at this stage, a foundation was laid for the operation of an expanded (multiple) model of drug trafficking on FM.

The third stage (2001-2007) of the development of the pharmaceutical supply system begins in 2001, when the government took steps to ensure the physical and socio-economic availability of drugs to the public. First, the Verkhovna Rada of Ukraine adopted Resolution No. 2564-III "On Information of the Cabinet of Ministers of Ukraine on Implementation of the Policy of State Regulation of Drugs and Medical Devices", which defined a program of measures to increase the availability of drugs and medical devices for the population, rational use of funds for the purchase of drugs, the development of a national list of essential (vital) drugs and medical products, and the introduction of a formulated system of medical supply for the population. At the end of 2001, a number of important RLAs were adopted that regulate pharmaceutical activity in the country as a whole and the circulation of drugs in particular:

- Resolution of the Cabinet of Ministers of Ukraine (CMU) No. 1482 "On Approving the National List of Essential (Essential) Drugs and Medical Devices";

- Order of the Ministry of Health of Ukraine No. 479 "On Amendments to the List of Medicines of Domestic and Foreign Production that may be Purchased by Health and Medical Institutions Fully or Partially Funded from the State and Local Budgets";

- Order of the Ministry of Health of Ukraine and the Ministry of Economy and European Integration of Ukraine No. 480/294 "On Approval of the List of Domestic and Imported Medicines and Medical Devices, Prices for which are Subject to State Regulation".

With the increase of financial stability and growth of the country's gross domestic product, the volume of domestic FM significantly increased during this period. Thus, as of January 1, 2003, 6620 registered drugs were registered in Ukraine, covering almost all pharmacotherapeutic groups, of which $40 \%$ were of domestic production. A large-scale process of step-by-step implementation of GMP requirements at such powerful enterprises as "Styrol", "Darnitsa", "Farmak", "Borschagovsky HFZ", "Indar" and others has begun to increase the quality requirements of drugs. On the whole, the macroeconomic situation in the Ukrainian FM improved significantly during this period, with an average annual growth rate of $21 \%$. Due to the increase in real incomes, the consumption of drugs increases - from \$ 23 to $\$ 48$ per person. However, these indicators are much lower than the existing indicators in the EU countries at the time (Czech Republic $-\$ 331$, Slovakia \$254, Poland - \$154).

An important step towards improving physical and socio-economic accessibility was the approval in 2006 of CMU Resolution No. 400 of the "Second Edition of the National List of Ba- 
sic Drugs and Medical Devices", which already contained 783 international non-proprietary or accepted names of active substances [12, 13]. Adopted at the end of 2007, "The Concept for the Development of the Pharmaceutical Sector of Healthcare in Ukraine" defined the task of developing a national policy for setting social priorities in providing the population with drugs, as well as implementing international standards (production, clinical, laboratory, distribution, pharmacy and other good practices) as the most important components in shaping a modern model of regulation of drug trafficking on FM.

With the onset of the global financial and economic crisis (2008), the fourth stage (20082013) of the development of the pharmaceutical supply system for the population began, which Ukraine has done quite successfully, building a strong structure within the country's macroeconomic complex. It should be noted that the beginning of this stage of development of the pharmaceutical supply system was characterized by the emergence of negative trends in FM, primarily due to its import dependence. Against the background of the gradual rise in drug prices, the Government of Ukraine has made it possible to remedy the situation by introducing a number of measures aimed at curbing purchase, wholesale, and retail prices. The process of improving the functioning of the state system of quality control of medicines also continued. In the event of worsening of the crisis phenomena on FM, the signing of the Memorandum on joining, accepting, amending and reviewing complaints within the framework of Rules for proper promotion by pharmaceutical companies to drug professionals by the representatives of 35 foreign and domestic pharmaceutical companies of the Ministry of Health of Ukraine looks positive in the summer of 2008. From this period it can be argued that Ukraine has laid the foundations for the implementation of important components in building a socially oriented model of the pharmaceutical business [14, 15]. Another important document that outlined the scale and irreversibility of changes in this direction was the Code of Ethics for Pharmaceutical Workers of Ukraine, which was adopted in September 2010 at the VII National Congress of Pharmacists of Ukraine [16]. This document for the first time in the history of domestic pharmacy declared a professionally and socially oriented model of behavior of pharmacy professionals in society in accordance with the modern paradigm of transformation of pharmaceutical assistance and services in the direction of increasing the social responsibility of pharmacies.

Consistency in the implementation of state policy in the system of pharmaceutical supply to the population was demonstrated by the fact that in 2010 by the order of the Ministry of Health of Ukraine No. 769, the "Concept of development of the pharmaceutical sector of health care of Ukraine for 2011-2020" was adopted, which was developed on behalf of the CMU in order to ensure the availability of high quality drugs, medical devices and medical equipment for the population [17]. improving the physical and socio-economic availability of drugs with proven efficacy, safety and quality through the use of drugs in accordance with drug forms, protocols and treatment standards, the introduction of state pricing regulations, and international standards for quality assurance of products and medical and pharmaceutical services. It should be noted that despite the import dependence of domestic FM and the consequences of the financial crisis in 2010-2012 in Ukraine, the physical availability of drugs has gradually increased. From a socio-economic point of view, the fact is that the domestic industry is showing a steady tendency for overproduction, which contributed to the gradual development of drug exports, especially to the countries of the former USSR. In order to solve the problem of low socio-economic availability of drugs, one of the perspective directions for the development of the system of pharmaceutical supply to the population is the introduction by the Government of the country of introduction of mechanisms for reimbursement of expenditures for drugs, a formulary system at all levels of provision of medical and pharmaceutical assistance and a model of compulsory state medical insurance [18].

Due to the transition of many quantitative positive changes to qualitative ones in 2011, Ukraine, represented by the State Drugs Service of Ukraine, became a full member of the International Pharmaceutical Inspection Co-operation Scheme (PIC/S). It should be noted that today from the list of countries of the former USSR, except for the Baltic states, which are members of the European Union, only Ukraine is part of the mentioned influential international organization. 
For the first time on domestic FM, in order to increase the economic availability of drugs, in April 2012 the Cabinet of Ministers adopted Resolution No. 340 "On the implementation of a pilot project on the introduction of state regulation of the prices of drugs for the treatment of persons with hypertension", which introduced the state regulation of the prices for drugs for that group. patients by setting the limit of wholesale prices for such drugs and working out a mechanism for partial reimbursement of their value. The implementation of this document was aimed at increasing the availability of drugs for low-income and socially unprotected patients with hypertension.

As a result of the Ukrainian government's earlier stated intention to implement a set of international good practice standards, primarily GMP, the number of licensees decreased from 151 to 111, respectively, in the period 2009-2013. At the same time, against the background of a decrease in the number of domestic producers, the volume of industrial production of products in monetary terms increased by almost $117 \%$ and exports - by $118 \%$. It should be noted that the share (\%) of drugs produced by domestic production in total volume on domestic FM increased from 25.3\% in 2009 to $35.5 \%$ in 2013 [19, 20]. Systematizing the results of the study, it can be argued that 2013 is one of the most successful periods in the development of Ukraine's pharmaceutical sector.

With the advent of the political, financial and socio-economic crisis in 2014, the fifth stage of the development of the pharmaceutical supply system for the population, which has been significantly influenced by external factors, begins. In 2014, the country experienced dramatic changes in virtually all areas of public relations. The systemic crisis in the country, the loss of territories due to the start of hostilities in the east of the country and the annexation of the Autonomous Republic of Crimea have led to significant structural changes in the system of pharmaceutical supply to the population. In 2014, as a result of fundamental changes in the exchange rate policy of the National Bank of Ukraine and as a result of the uncontrolled devaluation of the hryvnia (from February to August, more than $70 \%$ ), there was a significant decrease in the consumption of drugs and medical devices. This period was characterized by a decrease in sales volumes, both in US dollars and in kind. In 2015, the lowest FM drug volume was recorded in US dollars (US \$ 2.28 billion) (Fig. 1). In terms of in-kind drug sales, there was also a decline from 1.4 billion packs in 2012 to a minimum in 2015 (1.1 billion packs) and a gradual increase further to 1.3 in 2018 [21].

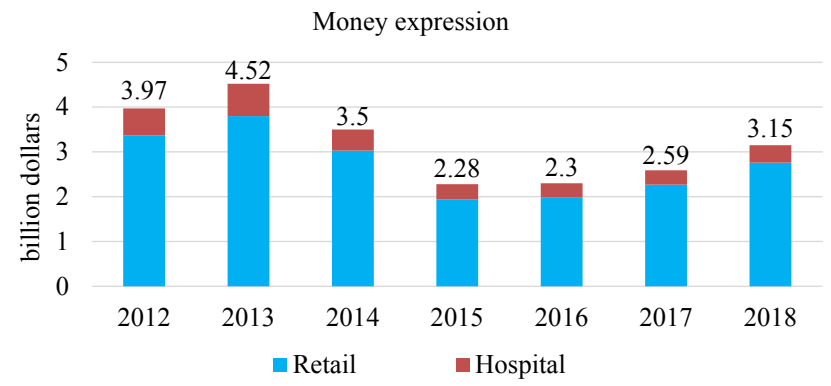

Fig. 1. Dynamics of retail sales and hospital supply of drugs in monetary terms, indicating the share of each of the segments

The increase (38.0\%) of hryvnia sales, which was observed in 2015, was due to the devaluation of the national currency. Amid the financial crisis, weakening of the executive branch, lack of a systematic approach to managing the industry, there was a sharp rise in drug prices and a sharp decline in drug consumption. It became very difficult to control the situation on FM, so the government introduced mechanisms of direct government regulation over a wide range of pharmaceutical activities, restrictions, differentiation of retail allowances, the declaration of wholesale and selling prices for drugs purchased for budgetary funds, the introduction of a $7 \%$ value added tax on drugs (April 2014), changing the rules for centralized drug procurement [22]. Under these conditions, the need for deregulation of the FM retail chain has become increasingly discussed in the pharmaceutical community.

It is well known that increasing regulatory pressure on FM subjects always automatically entails additional costs for businesses, with the direct consequence of reducing the socio-eco- 
nomic and further physical availability of drugs [23-25]. Significant structural shifts in drug use have occurred during the fifth period of the pharmaceutical supply system's development. Thus, with the gradual stabilization of the economic situation (2015-2016) in the country, Ukrainian consumers have increasingly preferred foreign-made drugs. An important event in the development of the national system of pharmaceutical supply to the population was the implementation of the government program "Available medicines" for persons suffering from cardiovascular diseases, type II diabetes, bronchial asthma since April 2017. The Affordable Care program was implemented against the background of reforming the entire healthcare system and implementing e-Health.

An important place in the development of the system of pharmaceutical supply to the population in the direction of implementation of modern norms and requirements was taken by the Cabinet of Ministers of Ukraine №1022 of December 5, 2018 "State strategy for the implementation of the state policy of providing the population with medicines for the period up to 2025" [17]. The document outlined policy commitments to ensure the availability and rational use of effective and safe drugs. First of all, it concerned the socio-economic availability of drugs, as physical availability was provided by a sufficient number of pharmacies in Ukraine. For example, as of January 1, 2019, 1 pharmacy serves an average of 2,044 citizens (Fig. 2) [21].

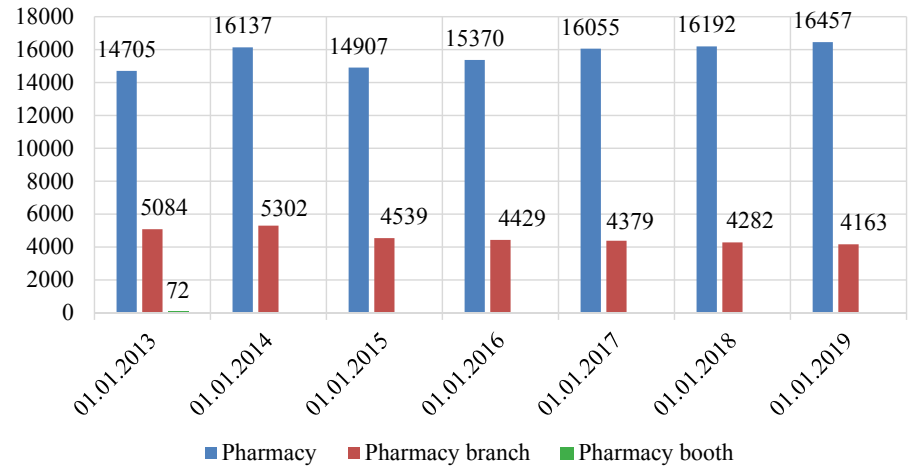

Fig. 2. Dynamics of the number of different types of shopping unit on FM Ukraine

Systematizing the assets of the fifth stage of development of the domestic system of pharmaceutical supply to the population, it is necessary to determine the following characteristics:

- introduction of e-Health elements in the organization of providing medical and pharmaceutical assistance to patients, in particular servicing the population by electronic prescriptions at the primary health care unit;

- the adoption in 2017 of a new National List of Essential Drugs (427 INN), which occupies a dominant position in the FM regulatory space and complies with WHO requirements (20thWHOEML (March 2017);

- the operation of the Government's Affordable Care Program;

- changes in the order of centralized procurement of drugs used to resolve socially significant issues through "ProZorro" and international agencies;

- consolidating the efforts of the professional community to enhance the influence of professional associations on the processes of organizing the provision of pharmaceutical assistance to the population and regulating pharmaceutical activity in the country;

- increasing the level of social responsibility of the pharmaceutical business and the formation of an updated model of capital-society relations on FM;

- implementation of European rules on the registration of drugs (simplified registration and mutual recognition procedure).

Thus, it can be argued that, despite the complexity of development, the domestic pharmaceutical supply system has shown, from one point of view, a significant dependence on external environmental factors, and on the other, significant development potential and the ability to respond quickly to numerous changes in factors of influence. 


\section{Discussion of the results}

On the basis of generalization of the processed material, we have identified the main five stages of the formation of the system of pharmaceutical supply of the population in terms of the formation of relationships between authorities and society from paternalistic to the emergence of elements of the patient-oriented model:

- 1990-1993 - chaotic development of FM and gradual emergence of market relations in the organization of provision of pharmaceutical services to the population, low level of efficiency of state regulation of pharmaceutical activity in its various aspects and directions;

- 1994-2000 - laying the legal, organizational, economic and administrative bases for the construction of a European-oriented model of pharmaceutical activity, such as an expanded (multiple) model of regulation of drug trafficking on FM;

- 2001-2007 - further development of a European-oriented model of pharmaceutical activity (gradual implementation of a set of good practices, first of all production) and an expanded (multiple) model of regulation of drug trafficking on FM against the background of gradual strengthening of state regulation of pharmaceutical activity at all stages of the promotion of drugs network;

$-2008-2013$ - the emergence and gradual development of socially oriented models of relations between different subjects of pharmaceutical relations, subject to the declaration by the state of European standards and requirements for the organization of accessible and effective medical and pharmaceutical care in accordance with the requirements of the WHO National Medicinal Policy;

- from 2014 to the present - crisis of relations between all subjects of relations in the system of pharmaceutical supply of the population against the background of systemic transformations in the state, strengthening of the role of public professional associations and critical raising of public expectations from the state regarding the organization of providing affordable medical care to the population and pharmaceutical assistance in the face of mass impoverishment.

The identified main stages of the formation of the pharmaceutical supply system in Ukraine and their characteristics allow to form in the future fundamentally new approaches to building rational, economically speaking, and at the same time socially responsible relations between different subjects on FM.

\section{Conclusions}

1. Based on our research, we have identified and outlined five stages in the development of the pharmaceutical supply system, which differ fundamentally across the spectrum of performance analysis criteria in building relationships between the state, civil society and the professional community.

2. It is proved that the stages of development of the domestic pharmaceutical supply system depend to a large extent on the nature of influence of external environmental factors: changes of political elites in the country, global and internal financial crises, changes of priorities of the state development, breaking of social consciousness of the population against the background of political crisis, etc.

3. It should be noted that the most important of the positive, first of all socio-economic, characteristics of development is the fourth stage of formation (2008-2013) of the domestic system of pharmaceutical supply of the population.

4. A promising direction for further research will be the development of theoretical and applied approaches to improving socially-oriented relations between different subjects of FM on the path from a paternalistic to a patient-oriented model of development of national health care in general and the system of pharmaceutical supply to the population in particular.

\section{Conflict of interest}

No conflict of interest.

\section{References}

[1] Susharyna, I. V., Nemchenko, A. S., Homenko, V. M. (2017). Identifying of the priority areas for improving of state and public regulation in pharmacy Pharmaceutical Review, 1, 38-44. doi: http://oi.org/10.11603/2312-0967.2017.1.7529 
[2] Tkachenko, N. O., Hromovyk, B. P. (2019). Place and role modeling of social responsibility in professional activity of pharmaceutical specialists. Management, Economics and Quality Assurance in Pharmacy, 2 (58), 28-36. doi: http://doi.org/10.24959/ uekj.19.4

[3] Kotvitska, A. A., Kubareva, I. V., Surikova, I. O. (2017). Study of the main stages of formation and development of social pharmacy in the world and in Ukraine. Pharmaceutical Review, 3, 70-76. doi: http://doi.org/10.11603/2312-0967.2017.3.8096

[4] Unhurian, L., Bielyaieva, O., Vyshnytska, I. et. al. (2018) Implementation of Standards of Good Pharmacy Practice in the World: A Review. Asian Journal of Pharmaceutics, 12 (1), 42-46.

[5] Bratishko, Yu. S. (2017). Social responsibility of pharmaceutical business and it regulation to the international quality standards. Science and society: collection of scientific articles, 106-111.

[6] Eades, C. E., Ferguson, J. S., O’Carroll, R. E. (2011). Public health in community pharmacy: A systematic review of pharmacist and consumer views. BMC Public Health, 11 (1). doi: http://doi.org/10.1186/1471-2458-11-582

[7] Bush, P. W., Daniels, R. (2017). Health care systems and transitions of care: implication on interdisciplinary pharmacy services. North Carolina medical journal, 78 (3), 177-180. doi: http://doi.org/10.18043/ncm.78.3.177

[8] Blouin, R. A., Adams, M. L. (2017). The Role of the Pharmacist in Health Care: Expanding and Evolving. North Carolina Medical Journal, 78 (3), 165-167. doi: http://doi.org/10.18043/ncm.78.3.165

[9] Kar, S., Pradhan, H., Mohanta, G. (2010). Concept of essential medicines and rational use in public health. Indian Journal of Community Medicine, 35 (1), 10-13. doi: http://doi.org/10.4103/0970-0218.62546

[10] Boryshchuk, V. O., Soloviov, O. S., Krasnianska, T. M. et. al. (2015). Doslidzhennia stanu orhanizatsii zabezpechennia naselennia likarskymy zasobamy v roky nezalezhnosti Ukrainy - stanovlennia farmatsevtychnoho rynku. Medychna informatyka ta inzheneriia, 3, 47-53.

[11] Haque, M. (2017) Essential Medicine Utilization and Situation in Selected Ten Developing Countries: A Compendious Audit. Journal International Society of Preventive \& Community Dentistry, 7 (4), 147-160.

[12] Samborskyi, O., Slobodyanyuk, M., Panfilova, H. et. al. (2019). Analysis of changes in market characteristics of Essential Medicines within the frames of state program of increasing availability of medicines in Ukraine. Journal of Pharmaceutical Sciences and Research, 11 (5), 1679-1686.

[13] WHO Model Lists of Essential Medicines. Available at: http://www.who.int/medicines/publications/essentialmedicines/en/

[14] Karanikolos, M., Mladovsky, P., Cylus, J., Thomson, S., Basu, S., Stuckler, D. et. al. (2013). Financial crisis, austerity, and health in Europe. The Lancet, 381 (9874), 1323-1331. doi: http://doi.org/10.1016/s0140-6736(13)60102-6

[15] Hemsley, S. (2018). Developing the role of the critical care pharmacist. The Pharmaceutical Journal. doi: http://doi.org/10.1211/ pj.2018.20204175

[16] Etychnyi kodeks farmatsevtychnykh pratsivnykiv Ukrainy (2010). Available at: http://nuph.edu.ua/wp-content/uploads/ 2015/04/etichnij_kodeks_pharm_pratsivnik.pdf

[17] Zakonodavstvo Ukrainy. Available at: https://zakon.rada.gov.ua

[18] Dalton, K., Byrne, S. (2017). Role of the pharmacist in reducing healthcare costs: current insights. Integrated Pharmacy Research and Practice, 6, 37-46. doi: http://doi.org/10.2147/iprp.s108047

[19] Bratishko, Yu. S., Posylkina, O. V., Kubasova A. V. (2014). Modern state of personnel management in pharmaceutical enterprises. Institutionelle Grundlagen für die Funktionierung der Ökonomik unter den Bedingungen der Transformation: Sammelwerk der wissenschaftlichen Artikel, 1, 148-151.

[20] Trygstad, T. (2017). Payment Reform Meets Pharmacy Practice and Education Transformation. North Carolina Medical Journal, 78 (3), 173-176. doi: http://doi.org/10.18043/ncm.78.3.173

[21] Kirsanov, D. (2019). Aptechnii rynok Ukrainy po itogam 2018 g.: Helicopter View. Ezhenedelnik Apteka, 2 (1173), 12-13.

[22] Prykhodko, O., Kirsanov, D. (2014). Derehuliatsiia farmrynku zabezpechyt dostupnist likiv dlia ukraintsiv. Ezhenedelnyk Apteka, 34 (955). Available at: https://www.apteka.ua/article/304660

[23] Excessive Pricing in Pharmaceutical Markets - Note by Ukraine (2018). Available at: https://one.oecd.org/document/DAF/ COMP/WD(2018)119/en/pdf

[24] Olasiuk, H. (2017). Competitive Forces on the Ukrainian Pharmaceutical Market: Evaluation Aspects Hanna Olasiuk, 2017. Journal of Applied Management and Investments, 6 (3), 186-196.

[25] Ukrainian Pharmaceutical (2017). Available at: https://ucci.org.ua/uploads/files/59c37786bb26e252265053.pdf

Received date 21.08.2019

Accepted date 16.08.2019

Published date 20.09.2019
(C) The Author(s) 2019

This is an open access article under the CC BY license (http://creativecommons.org/licenses/by/4.0). 